\title{
Tipología textual e identificación de nuevos marcadores discursivos del español
}

\author{
Text typology and identification of new discourse markers in Spanish \\ Gracia Piñero Piñero ${ }^{1}$, Marina Díaz Peralta ${ }^{2}$ \\ ${ }^{1}$ Universidad de Las Palmas de Gran Canaria, Departamento de Filología Española, \\ Clásica y Arabe, Las Palmas de Gran Canaria, España, \\ e-mail: gpinero@dfe.ulpgc.es \\ ${ }^{2}$ Universidad de Las Palmas de Gran Canaria, Departamento de Filología Española, \\ Clásica y Arabe, Las Palmas de Gran Canaria, España, \\ e-mail:mdiaz@dfe.ulpgc.es
}

Tras el análisis de un corpus de textos periodísticos pertenecientes al género del artículo de opinión, resulta evidente la necesidad de ampliar los inventarios de marcadores del español para incorporar unidades que, sin estar catalogadas, son capaces también de sacar a la luz relaciones semántico-pragmáticas existentes entre los miembros del discurso. Partiendo de un sólido marco teórico, hemos advertido la presencia de las siguientes unidades aún no inventariadas: se trata de, por así decirlo, hablando de $+S N$, no olvidemos que, de lo que se colige I deduce que y al grano.

Palabras clave: tipología textual, identificación, marcadores discursivos, español.

After analysing various different argumentative texts written in Spanish, it is evident that the existing lists of discourse markers used need to be extended in order to incorporate noncatalogued units capable of bringing about semantic-pragmatic relationships between members of the discourse. The application of a solid theoretical framework revealed that the following expressions function as discourse markers, although they have not been recognised as such: se trata de (this is about), por así decirlo (so to say), hablando de (speaking about) + nominal group, no olvidemos que (let's not forget that), de lo que se colige / deduce que (it follows that) y al grano (straight to the point).

Key words: text typology, identification, discourse markers.

\section{INTRODUCCIÓN}

Coincidimos con Hyde (2002: 39) en que el análisis de corpora de textos pertenecientes a una misma tipología pone de manifiesto la conveniencia de que los inventarios de marcadores existentes se amplíen para acoger unidades que nunca han sido incluidas, a pesar de que son efectivamente utilizadas como tales. El tratamiento de textos concretos descubre, por tanto, alternativas capaces también de sacar a la luz relaciones semántico-pragmáticas existentes entre los miembros del discurso. 
Y es que, en efecto, todo género textual dispone de una serie de convenciones que se manifiestan en todos los planos y que contribuyen a su caracterización. Obviamente, estas especificidades se observan también en el uso de los marcadores del discurso, puesto que, según se ha demostrado (Calsamiglia y Tusón 1999 y Domínguez García 2002, por ejemplo), existe una relación entre la tipología textual y la preferencia por determinadas funciones semántico-pragmáticas.

Lo cierto es que las investigaciones tradicionales sobre los marcadores del discurso ya sugerían la necesidad de abrir sus puertas a determinados elementos que desempeñan funciones equivalentes a los ya inventariados. En esta línea, los autores de estas clasificaciones suelen afirmar que no están catalogadas todas las unidades que podrían integrarse en esta categoría, puesto que "acometer esta empresa de un modo exhaustivo resultaría casi tan utópico -hay que admitirlo de entrada- como ponerle puertas al campo" (Zorraquino y Portolés 1999: 4056) ${ }^{1}$.

En esta línea, nuestro trabajo tiene como objetivo, en primer lugar, verificar la presencia en los textos de expresiones no catalogadas capaces de funcionar como elementos relacionantes; $y$, en segundo lugar, detectar posibles funciones textuales aún no reconocidas.

Para ello, analizaremos un corpus de textos argumentativos escritos, pertenecientes al estilo periodístico y, en concreto, al género del artículo de opinión, extraídos de tres suplementos dominicales de difusión nacional: Magazine, ABC y El País Semanal. La elección de este género textual está motivada por factores diversos. En primer lugar, por el predominio de la técnica argumentativa, a través de la cual el autor expone un pensamiento lógico completamente desarrollado; en segundo lugar, por el convencimiento de que en ellos encontraremos una amplia representación de

1 Muestra de la dificultad de catalogar todas las posibles funciones discursivas de los marcadores la cons-
tituye la disparidad existente entre los inventarios recogidos en los estudios citados. Así, por ejemplo, la
expresión ya digo, que actúa como indicador de la vuelta a un tópico del discurso que previamente había
sido interrumpido, es recogida por Fuentes (1996: 56-57) y, sin embargo, no figura en los restantes inven-
tarios, a pesar de que es evidente su funcionamiento como marcador:
Da la impresión de que a los creyentes les trae más bien sin cuidado la calidad estética de las manifesta-
ciones y los rituales de su fe. A algunos incrédulos nos ocurre lo contrario: carecemos del menor interés
personal en la religión, pero nos emocionan las obras maestras del arte religioso. No hace falta creer en el
Juicio Final ni en la resurrección de los muertos para conmoverse con el Réquiem de Mozart o con el de
Fauré, con el apocalíptico Réquiem alemán de Brahms o el no menos tremendo War Réquiem de Britten.
La devoción por la Virgen María se me pasó hacia los 11 o 12 años, en la época en que hacíamos altares
durante el mes de mayo, pero hay pocas obras musicales que me suman en una congoja tan intensa como
el Stabat Mater de Pergolesi.

Pero me temo, ya digo, que esta afición por la música religiosa no alcanza a los interesados espiritualmente en la religión, o a los encargados de su culto.

Antonio Muñoz Molina, Días de pasión Igualmente sucede con la estructura el caso es que, la cual se incluye en la clasificación realizada por Fuentes (1987: 139) y, sin embargo, se excluye de los inventarios posteriores, cuando es innegable su condición de relacionante:

[...] muy a menudo el despertador suena y yo paso, pero como tengo mala conciencia dejo la radio puesta. Para cuando me levanto, un par de horas después, los horrores informativos han penetrado en mi organismo [...]. A menudo, entre dos malas noticias, se cuela una curiosidad que, posiblemente, olvido durante la jornada hasta que en un momento dado, zas, ahí la tengo de nuevo, e ignoro si ocurrió de verdad o acabo de inventármela.

El caso es que acaba de venirme a la mente la siguiente frase: los hombres no van al ginecólogo. No puede ser que lo haya dicho el locutor, porque, como bien sabemos, el ginecólogo solo se ocupa de los bajos fondos de las señoras. 
las unidades objeto de análisis; en tercer lugar, porque se trata de textos que abordan temas de actualidad, de modo que parece lógico suponer a priori que proporcionarán unidades comunes y habituales en el español de hoy; y, por último, porque todos ellos están firmados por autores nacionales de reconocido prestigio y, por tanto, por usuarios competentes de la lengua española.

Naturalmente, cualquier pretensión de promover nuevas incorporaciones a los inventarios al uso debe sustentarse en un análisis riguroso que confirme su pertenencia en tanto que se adecuan a los principios comúnmente establecidos para la clase de los marcadores del español (Mederos Martín 1988; Fuentes 1987, 1996; Pons Bordería 1998; y Martín Zorraquino y Portolés 1999)². Esta labor nos enfrenta, como repetidas veces se ha afirmado, a una tarea ardua y compleja, debido no solo a las diferencias terminológicas sino también, y muy especialmente, a la discrepancia de criterios empleados en la definición de estos elementos.

En nuestro caso, atenderemos a las siguientes pautas para corroborar la existencia de un marcador:

a. La característica sintáctica básica es la función supraenunciativa ${ }^{3}$, lo que explica que la eliminación del marcador no afecte la gramaticalidad de los segmentos entre los que se inserta (Pons Bordería 1998: 50). Suele relacionarse con este primer parámetro la distinción entre marcadores parentéticos e integrados ${ }^{4}$ (Montolío 2001: 35).

b. Poseen un valor deíctico anafórico.

c. Tienen un significado procedimental ${ }^{5}$, que facilita al receptor el correcto procesamiento de la información del texto ${ }^{6}$.

d. Son léxica y gramaticalmente invariables. Esta cualidad, como se deduce de los estudios (véase, por ejemplo, Martín Zorraquino 1998: 47), se erige en un procedimiento fundamental para determinar la naturaleza discursiva de una expresión lingüística. Ahora bien, como tendremos ocasión de constatar posteriormente, esta

\footnotetext{
2 Cuando se trata de estudiar los marcadores desde una perspectiva interlingüística, es posible recurrir a otros marcos teóricos más amplios y generosos (véase, en este sentido, Piñero Piñero 2001).

3 Sin embargo, cabría plantearse si verdaderamente el hecho de que una estructura no funcione solo como un elemento periférico anula su condición de marcador, pues expresiones como por eso/ esto/ello son capaces de actuar simultáneamente como marcadores y como adyacentes verbales.

${ }^{4}$ Recordemos que parentéticos son aquellos marcadores que van entre pausas o signos de puntuación en el texto escrito y que, por ello, gozan de una gran movilidad dentro del enunciado; por su parte, los integrados en la oración no van entre pausas y cuentan con un elemento subordinante.

5 Este concepto ha sido desarrollado por la teoría de la relevancia (Sperber y Wilson 1986; Wilson y Sperber 1993) y aplicado al estudio de los marcadores por, entre otros, Blakemore (1987) y Blass (1990).

No obstante, se ha de tener presente que la ausencia de significado conceptual tiene una importancia relativa a la hora de determinar la pertenencia de una unidad a la clase funcional de los marcadores, como se desprende de las siguientes palabras de Martín Zorraquino y Portolés (1999: 4059):

De todos modos, no siempre es sencillo discernir si una unidad lingüística contribuye o no a las condiciones de verdad de un discurso o si su significado es de procesamiento y no conceptual; por ello, la lista de los marcadores del discurso, aun coincidiendo en los criterios de delimitación de la clase, puede presentar variaciones.

${ }^{6}$ En relación con los dos últimos parámetros señalados, conviene precisar que, a pesar de que son presentados como características diferentes en las fuentes consultadas, constituyen, obviamente, conceptos complementarios en la medida en que el valor anafórico es consustancial al significado procedimental del marcador. Sin embargo, se ha de señalar que, como observaremos a lo largo de nuestro análisis, las unidades que actúan como marcadores pueden, también, contribuir a las condiciones de verdad del discurso.
} 
invariabilidad no tiene por qué plantearse en términos absolutos pues en buena parte de las ocasiones se trata de un proceso que discurre por fases definidas por un mayor o menor grado de gramaticalización. Por consiguiente, una cierta variabilidad no descarta la pertenencia de una unidad a la clase de los marcadores.

e. Ligada a la ausencia de significado semántico pleno, está la imposibilidad que presentan los marcadores de ser focalizados mediante estructuras ecuacionales (Gutiérrez Ordóñez 1997: 37), en las que se conviertan en la magnitud que se pretende resaltar.

\section{ANÁLISIS}

En estas páginas nos ocuparemos exclusivamente de aquellos contextos en los que el marcador establece una relación supraoracional y, por tanto, conecta enunciados o párrafos. Dada la importancia que presenta el concepto discursivo de enunciado para nuestro análisis, es preciso señalar sus límites formales. Para ello, recurriremos a criterios adsegmentales, pues, como es de sobra conocido, los argumentos gramaticales tradicionales no son válidos para su delimitación. En definitiva, entendemos por enunciado la porción de discurso delimitada por un punto y coma o por un punto (R.A.E. 1999: 56; Mederos 1988: 215; Díaz Peralta y García Domínguez 2004)7.

El examen de nuestro corpus revela que las siguientes unidades lingüísticas, aún no inventariadas, se ajustan a los criterios establecidos para la definición del marcador y, por ello, se comportan como auténticos relacionantes: se trata de, por así decirlo, hablando de + SN, no olvidemos que, de lo que se colige / deduce que y al grano. Estas unidades revelan, además, una heterogeneidad estructural, que corrobora la resistencia de esta categoría a ser considerada como una clase formal ${ }^{8}$.

\subsection{ADECUACION DE LAS NUEVAS UNIDADES A LOS PARAMETROS DEFINITORIOS DEL MARCADOR}

La primera de las secuencias localizada en nuestro corpus es la expresión sintácticamente integrada y, por ello, sin movilidad, se trata de:

Cuando se inventó, nadie sospechaba que el teléfono acabaría teniendo la importancia que hoy tiene [...]. Esa conversión en objeto sin el cual parece que sea imposible vivir se ha ido extendiendo a otros ámbitos de la telefonía. Me refiero a los teléfonos de servicio público. [...]. La información del tiempo o del tráfico vía telefónica se ha convertido en algo normal y, en un ámbito más espiritual, casi todas las sociedades avanzadas cuentan con un servicio de teléfono de la esperanza. Se trata de un teléfono que, como indica su nombre, practica una forma de caridad espiritual telefónica que ha salvado a más de uno.

Quim Monzó, 098.

\footnotetext{
7 Aunque no hemos hallado ningún ejemplo en nuestro corpus, García Domínguez y Marrero Pulido (2005) consideran también los dos puntos como signo inequívoco del fin de enunciado.

${ }^{8}$ A este respecto, afirma Pons Bordería (1998: 49): "Pocos autores se manifiestan a favor de la consideración de los conectores como clase formal, debido a las dificultades para formar un paradigma homogéneo. Más frecuente es la postura de considerarlos como clase funcional".
} 
Podemos constatar en este fragmento la función supraenunciativa de esta unidad y el hecho de que su omisión no repercuta sobre la gramaticalidad de la secuencia ${ }^{9}$ :

Cuando se inventó, nadie sospechaba que el teléfono acabaría teniendo la importancia que hoy tiene [...]. Esa conversión en objeto sin el cual parece que sea imposible vivir se ha ido extendiendo a otros ámbitos de la telefonía. Me refiero a los teléfonos de servicio público. [...]. La información del tiempo o del tráfico vía telefónica se ha convertido en algo normal y, en un ámbito más espiritual, casi todas las sociedades avanzadas cuentan con un servicio de teléfono de la esperanza. $\varnothing$ un teléfono que, como indica su nombre, practica una forma de caridad espiritual telefónica que ha salvado a más de uno.

Quim Monzó, 098

Asimismo, se confirma su valor deíctico anafórico y su significado procedimental. De otra parte, se verifica su invariabilidad léxica y gramatical, a pesar de que en su estructura, constituida por [verbo + preposición], intervienen elementos que en otros contextos poseen un significado semántico pleno. Esta lexicalización también nos permite apuntar que no estamos ante constituyentes inmediatos de la oración (Pons Bordería 1998: 50), ya que, en nuestra opinión, la estructura presenta el mismo grado de lexicalización que cualquier locución. Por último, nuestro análisis muestra, igualmente, la resistencia de la unidad se trata de a la focalización mediante estructuras ecuacionales:

* Se trata de es lo que un teléfono.

En definitiva, hemos podido corroborar empíricamente la pertenencia de se trata de a la categoría de los marcadores, a pesar de su ausencia reiterada de las nóminas (Fuentes 1987, 1996; Casado Velarde 1998; Martín Zorraquino y Portolés 1999).

En el texto que exponemos a continuación podemos, asimismo, observar que este elemento de relación se combina con otra expresión, por así decirlo, ausente también de los inventarios y que, como comprobaremos, puede ser considerada igualmente marcador $^{10}$ :

Los crímenes y los abusos de los pistoleros y de sus chusmas de adictos impunes no han sido solo brutales: también han sido políticos, en su sentido más estricto. [...]. Se trata, por así decirlo, de una política municipal, de una política electoral: se mató a quien amenazaba con conseguir muchos votos, y se persigue y se amenaza ahora con la finalidad estrictamente práctica no ya de hacer méritos ante la horda, sino de evitar que ciertas personas se atrevan a presentar sus candidaturas, o que puedan hacer una campaña electoral libre de amenazas y sabotajes.

Antonio Muñoz Molina, Vísperas municipales

\footnotetext{
9 Entendemos por gramaticalidad que la estructura resultante tras la omisión del marcador sea sintácticamente aceptable. Por lo que se refiere al contenido semántico-pragmático del enunciado, no podemos olvidar que la presencia del marcador solo explicita o refuerza la conexión implícita existente entre los enunciados (Montolío 1998: 103; Marrero Pulido 2004).

10 Como es sabido, esta posibilidad que tienen los relacionantes discursivos de yuxtaponerse, combinarse o acumularse está recogida en algunos de los estudios ya mencionados (Martín Zorraquino y Portolés 1999: 4066; Domínguez García 2002: 37).
} 
Una vez más constatamos la función supraenunciativa de por así decirlo y, con ella, que la eliminación de la secuencia objeto de estudio no altera la gramaticalidad del enunciado:

Los crímenes y los abusos de los pistoleros y de sus chusmas de adictos impunes no han sido solo brutales: también han sido políticos, en su sentido más estricto. [...]. Se trata, $\varnothing$, de una política municipal, de una política electoral: se mató a quien amenazaba con conseguir muchos votos, y se persigue y se amenaza ahora con la finalidad estrictamente práctica no ya de hacer méritos ante la horda, sino de evitar que ciertas personas se atrevan a presentar sus candidaturas, o que puedan hacer una campaña electoral libre de amenazas y sabotajes.

Antonio Muñoz Molina, Vísperas municipales

Parece claro también su valor anafórico, su significado procedimental y su invariabilidad léxica y gramatical; de igual modo, por así decirlo no puede ser focalizado:

* Por así decirlo es lo que se trata de una política municipal.

Nuestro análisis continúa con el examen de la expresión hablando de $+S N$, de estructura [verbo + preposición $+S N]$ :

La ciencia ha avanzado una barbaridad, pero, paralelamente, la ilusión de panacea la hace retroceder al tiempo de las pirámides o del ocultismo. Hablando de ocultismo, ¿qué significado puede tener hoy el espectáculo de la exhibición de los "restos incorruptos" de Juan XXIII?

Manuel Rivas, El coqueteo con la inmortalidad

Al igual que en los marcadores anteriores, es posible corroborar, para esta estructura parentética, su funcionamiento extraenunciativo, que, una vez más, provoca que su supresión no altere la gramaticalidad del enunciado:

La ciencia ha avanzado una barbaridad, pero, paralelamente, la ilusión de panacea la hace retroceder al tiempo de las pirámides o del ocultismo. $\varnothing$, ¿ocultismo? ¿qué significado puede tener hoy el espectáculo de la exhibición de los "restos incorruptos" de Juan XXIII?

Manuel Rivas, El coqueteo con la inmortalidad

Del mismo modo, se advierte su valor relacionante, su claro significado procedimental, una invariabilidad léxica y gramatical fuera de duda y, cómo no, la imposibilidad de ser focalizada:

*Hablando de ocultismo es lo que el significado puede tener [...].

Antes de proseguir con el análisis, parece necesario resaltar que el doble valor anafórico que se deriva, de una parte, de la expresión hablando de, y, de otra, del sintagma nominal que necesariamente la acompaña y que reitera un elemento discursivo aparecido en el pre-texto, no tiene por qué poner en entredicho, como para otros casos se ha hecho, el valor de esta unidad como marcador ${ }^{11}$.

11 Resultan muy aclaradoras a este respecto las precisiones que hace Domínguez García (2002: 65) sobre la doble conexión anafórica favorecida por el conector y por el deíctico en el caso de además de esto/ello. 
Continuamos con el examen de la secuencia sintácticamente integrada no olvidemos que, cuya estructura responde a [adverbio + verbo + conjunción subordinante]:

Aparte del impacto negativo que ciertas imágenes de violencia o pornografía ejercen en determinados niños y niñas, creo que la televisión no es tan poderosa como nos advierten ni tan apocalíptica como otros temen. No olvidemos que los cuentos infantiles más populares están colmados de la violencia más gráfica.

Luis Rojas Marcos, Niños y televisión

Hemos de hablar una vez más de función extraenunciativa y de que, como veíamos en los casos anteriores, la supresión de la unidad postulada como marcador no altera la gramaticalidad de las secuencias que vincula:

Aparte del impacto negativo que ciertas imágenes de violencia o pornografía ejercen en determinados niños y niñas, creo que la televisión no es tan poderosa como nos advierten ni tan apocalíptica como otros temen. $\varnothing$ los cuentos infantiles más populares están colmados de la violencia más gráfica.

Luis Rojas Marcos, Niños y televisión

Asimismo, hemos de mencionar su valor anafórico, su significado procedimental, así como su alto grado de invariabilidad léxica y, aunque en menor medida, gramatical $^{12}$. En lo que al último parámetro considerado se refiere, no olvidemos que no admite, de ningún modo, la focalización:

* No olvidemos que es lo que los cuentos infantiles están colmados de la violencia más gráfica.

Nuestra observación continúa con la secuencia de lo que se colige / deduce que. $\mathrm{Al}$ igual que otras expresiones analizadas, su estructura, [preposición + lo + relativo + verbo + conjunción subordinante], contiene dos elementos deícticos que, en nuestra opinión, refuerzan y no anulan el valor de la expresión en su totalidad como marcador:

Pero por pura lógica contable, los billetes que al final acaban marcando la pauta son siempre los que empiezan por uno, seguido de más o menos ceros: cien dólares, mil dólares; mil pesetas, diez mil pesetas... Así pues, el de cien euros es, además de verde, el que más posibilidades tiene de marcar la pauta. De lo que se colige que el inminente cambio de moneda conllevará una revalorización de la lechuga y del lagarto.

Quim Monzó, Lagartos y lechugas

\footnotetext{
12 Recordemos una vez más, a este propósito, que la invariabilidad es una cuestión muy debatida cuando se trata de fijar la pertenencia de una unidad al inventario de los marcadores, como se comprueba, por ejemplo, en la polémica relacionada con el tratamiento como marcador de expresiones tales como por esto, por eso, por ello (Fuentes 1987, 1986; Martín Zorraquino 1998; Martín Zorraquino y Portolés 1999; Domínguez García 2002). Se ha de señalar, igualmente, que la ausencia de invariabilidad gramatical no es un obstáculo para Fuentes (1996: 41) a la hora de incluir entre los relacionantes de causalidad poniendo (puestas, si pones) las cosas así.
} 
Que quede claro que las campañas de persecución de los fumadores no me caen simpáticas. Pero es que nuestro personaje, en el fondo, no es fumador. Lo chocante de él es que de hecho apenas fuma. Si se fumase su cigarrillo con deleite, una calada tras otra, nada que decir. Pero es que no se los fuma. Los enciende, pero con la misma intensidad con la que los saca del paquete luego se olvida de ellos. De lo que se deduce que fumar-lo que se dice fumar- no le gusta.

Quim Monzó, El que no fuma

En este segmento, la presencia de un punto confirma la función supraenunciativa de la unidad, cuya eliminación no provoca alteraciones en la gramaticalidad del enunciado:

Pero por pura lógica contable, los billetes que al final acaban marcando la pauta son siempre los que empiezan por uno, seguido de más o menos ceros: cien dólares, mil dólares; mil pesetas, diez mil pesetas... Así pues, el de cien euros es, además de verde, el que más posibilidades tiene de marcar la pauta. $\varnothing$ el inminente cambio de moneda conllevará una revalorización de la lechuga y del lagarto.

Quim Monzó, Lagartos y lechugas

Que quede claro que las campañas de persecución de los fumadores no me caen simpáticas. Pero es que nuestro personaje, en el fondo, no es fumador. Lo chocante de él es que de hecho apenas fuma. Si se fumase su cigarrillo con deleite, una calada tras otra, nada que decir. Pero es que no se los fuma. Los enciende, pero con la misma intensidad con la que los saca del paquete luego se olvida de ellos. $\varnothing$ fumar -lo que se dice fumar- no le gusta.

Quim Monzó, El que no fuma

Se desprende, asimismo, de las muestras textuales el valor deíctico y procedimental, la invariabilidad gramatical, aunque no léxica, y, por último, la imposibilidad de que la expresión se focalice mediante estructuras ecuacionales:

* De lo que se deduce / colige que es lo que el inminente cambio de moneda conllevará [...].

*De lo que se deduce/colige que es lo que fumar no le gusta.

La última expresión objeto de análisis, al grano, de estructura [preposición + artículo + sustantivo], responde igualmente a los parámetros establecidos:

Al fin, colega, me digo. Llevas años blasfemando en arameo por culpa de los párrocos, obispos o sujetos a quien corresponda, que mantienen cerradas iglesias y catedrales impidiéndote visitarlas. Los malajes. Y no es que uno se incline al agua bendita. De eso me curé leyendo, jovencito, y terminaron por rematarlo veintiún años de mochila, cuando me ganaba el jornal enseñando muertos en el telediario, y me hubiera encantado -lo juro por mi perro- que de veras hubiera un responsable de todo aquello en alguna parte, para dirigirme a él y ciscarme en sus muertos. El caso es que así, leyendo, viajando, mirando alrededor, aprendí lo que comentaba aquí hace unas semanas: que las iglesias y las catedrales forman parte de mis diez mil años de memoria, y que sin ellas, sin lo bueno y lo malo que representan y recuerdan, monumento a la fe, a la historia, al espíritu noble del hombre y también a su capacidad de manipulación y engaño, es imposible entender el mundo actual, el Mediterráneo, Europa y lo que todavía llamamos Occidente. Por eso hace mucho que defiendo en esta página la asignatura de Religión. No como la plantean mis primos -no me hagan señalar-, currándose un modo de seguir mojando pan en todas las salsas sin perder el paso de baile con los nuevos ritmos. No. Hablo de la religión católica como cultura 
objetiva. Como explicación tan imprescindible de lo que fuimos y lo que somos. Al grano. Les decía que fastidia mucho llegar a un sitio, dispuesto a visitar la iglesia románica, la catedral o lo que sea, y a diferencia de lo que suele ocurrir en Francia o Italia, encontrártelas cerradas; y a menos que le comas el tarro al secretario del ayuntamiento o a un sacristán que salga a por tabaco, vas listo.

Arturo Pérez Reverte, El retablo intermitente de Murcia

Efectivamente, no cabe duda de la función supraenunciativa de la unidad parentética propuesta y de que su supresión no altera la gramaticalidad de las secuencias que relaciona:

Al fin, colega, me digo. Llevas años blasfemando en arameo por culpa de los párrocos, obispos o sujetos a quien corresponda, que mantienen cerradas iglesias y catedrales impidiéndote visitarlas. Los malajes. Y no es que uno se incline al agua bendita. De eso me curé leyendo, jovencito, y terminaron por rematarlo veintiún años de mochila, cuando me ganaba el jornal enseñando muertos en el telediario, y me hubiera encantado -lo juro por mi perro- que de veras hubiera un responsable de todo aquello en alguna parte, para dirigirme a él y ciscarme en sus muertos. El caso es que así, leyendo, viajando, mirando alrededor, aprendí lo que comentaba aquí hace unas semanas: que las iglesias y las catedrales forman parte de mis diez mil años de memoria, y que sin ellas, sin lo bueno y lo malo que representan y recuerdan, monumento a la fe, a la historia, al espíritu noble del hombre y también a su capacidad de manipulación y engaño, es imposible entender el mundo actual, el Mediterráneo, Europa y lo que todavía llamamos Occidente. Por eso hace mucho que defiendo en esta página la asignatura de Religión. No como la plantean mis primos -no me hagan señalar-, currándose un modo de seguir mojando pan en todas las salsas sin perder el paso de baile con los nuevos ritmos. No. Hablo de la religión católica como cultura objetiva. Como explicación tan imprescindible de lo que fuimos y lo que somos.

$\varnothing$. Les decía que fastidia mucho llegar a un sitio, dispuesto a visitar la iglesia románica, la catedral o lo que sea, y a diferencia de lo que suele ocurrir en Francia o Italia, encontrártelas cerradas; y a menos que le comas el tarro al secretario del ayuntamiento o a un sacristán que salga a por tabaco, vas listo.

Arturo Pérez Reverte, El retablo intermitente de Murcia

De igual modo, resulta evidente su valor anáforico, su significado procedimental y su completa invariabilidad léxica y gramatical. En este caso resulta imposible corroborar el último parámetro, dado que, en este texto, la expresión al grano se presenta en un enunciado independiente.

\subsection{FUNCION TEXTUAL DE LAS UNIDADES PROPUESTAS}

Una vez comprobada la pertenencia de estas unidades a la clase funcional de los marcadores, el siguiente paso será, como ya expusimos, precisar su función textual o, lo que es lo mismo, determinar qué instrucciones proporcionan para la decodificación del mensaje. Un mecanismo conveniente para establecer el valor procedimental de estos marcadores es la búsqueda de equivalencias con otras unidades reconocidas tradicionalmente como tales ${ }^{13}$.

\footnotetext{
13 Como explica Mederos (1988: 244) a propósito de unidades como así pues, de ahí/aquí, por esto/eso/ ello, adverbiales en función conjuntiva, "situamos dentro de la conexión estas expresiones por ser conmutables por otras de valor consecutivo".
} 
Parece conveniente adelantar que para algunas unidades no ha sido posible encontrar equivalentes porque a sus funciones textuales añaden matices ausentes de los inventarios al uso, pues, como afirma Casado Velarde (1998: 64), "no existe un catálogo exhaustivo de funciones textuales".

Veamos los marcadores con los que pueden alternar las unidades que hemos descubierto:

Cuando se inventó, nadie sospechaba que el teléfono acabaría teniendo la importancia que hoy tiene. [...]. Esa conversión en objeto sin el cual parece que sea imposible vivir se ha ido extendiendo a otros ámbitos de la telefonía. Me refiero a los teléfonos de servicio público. [...] La información del tiempo o del tráfico vía telefónica se ha convertido en algo normal y, en un ámbito más espiritual, casi todas las sociedades avanzadas cuentan con un servicio de teléfono de la esperanza. Se trata de (esto es / es decir / a saber) un teléfono que, como indica su nombre, practica una forma de caridad espiritual telefónica que ha salvado a más de uno.

Quim Monzó, 098

Como se deduce de estas equivalencias, podemos definir este nuevo marcador, se trata de, como un reformulador, en tanto que el hablante lo utiliza para indicar que el segundo miembro del discurso se presenta como la secuencia más importante, porque es la que orienta la interpretación del receptor (Fuentes: 1996: 65). Además, creemos que funciona como reformulador explicativo, puesto que presenta el enunciado que introduce como una aclaración o explicación de lo que se ha querido decir en el enunciado anterior (Casado Velarde 1991).

Por lo que respecta a hablando de $+S N$ y a no olvidemos que, la búsqueda de equivalencias demuestra que, aun estando ausente de las clasificaciones, se comportan como marcadores estructuradores. Este tipo ha sido definido por Alcina y Blecua (1975:86) como jerarquizadores de la información según su grado de importancia semántica. El primero de ellos, hablando de $+S N$, sería un estructurador de carácter digresor, dado que jerarquiza la información que introduce presentándola como un comentario lateral en relación con el tópico principal del discurso (Casado Velarde 1998: 65). El marcador no olvidemos que se inscribiría entre los comentadores, ya que, como sucede con su equivalente pues, presenta el enunciado en que se inserta "como un comentario nuevo e informativamente valioso con respecto del discurso que lo precede" (Martín Zorraquino y Portolés 1999: 4083).

La ciencia ha avanzado una barbaridad, pero, paralelamente, la ilusión de panacea la hace retroceder al tiempo de las pirámides o del ocultismo. Hablando del ocultismo (por cierto / a propósito), ¿qué significado puede tener hoy el espectáculo de la exhibición de los "restos incorruptos" de Juan XXIII?

Manuel Rivas, El coqueteo con la inmortalidad

Aparte del impacto negativo que ciertas imágenes de violencia o pornografía ejercen en determinados niños y niñas, creo que la televisión no es tan poderosa como nos advierten ni tan apocalíptica como otros temen. No olvidemos que (pues) los cuentos infantiles más populares están colmados de la violencia más gráfica.

Luis Rojas Marcos, Niños y televisión 
En lo que se refiere a de lo que se colige / deduce que, nos hallamos ante un nuevo conector perteneciente al grupo de los consecutivos, al presentar el enunciado como resultado de otro anterior.

Pero por pura lógica contable, los billetes que al final acaban marcando la pauta son siempre los que empiezan por uno, seguido de más o menos ceros: cien dólares, mil dólares; mil pesetas, diez mil pesetas... Así pues, el de cien euros es, además de verde, el que más posibilidades tiene de marcar la pauta. De lo que se colige que (en consecuencia / por tanto / por consiguiente) el inminente cambio de moneda conllevará una revalorización de la lechuga y del lagarto.

Quim Monzó, Lagartos y lechugas

Que quede claro que las campañas de persecución de los fumadores no me caen simpáticas. Pero es que nuestro personaje, en el fondo, no es fumador. Lo chocante de él es que de hecho apenas fuma. Si se fumase su cigarrillo con deleite, una calada tras otra, nada que decir. Pero es que no se los fuma. Los enciende, pero con la misma intensidad con la que los saca del paquete luego se olvida de ellos. De lo que se deduce que (en consecuencia / por tanto / por consiguiente) fumar -lo que se dice fumar- no le gusta.

Quim Monzó, El que no fuma

En el caso de la expresión por así decirlo, la búsqueda de equivalentes se revela infructuosa pues, a pesar de que puede figurar en la clase de los marcadores reformulativos, que explican el contenido que se pretende hacer llegar al oyente, añade un matiz diferenciador: define en términos aproximados una idea o concepto presente en el pre-texto.

Los crímenes y los abusos de los pistoleros y de sus chusmas de adictos impunes no han sido solo brutales: también han sido políticos, en su sentido más estricto. [...]. Se trata, por así decirlo, de una política municipal, una política electoral: se mató a quien amenazaba con conseguir muchos votos, y se persigue y se amenaza ahora con la finalidad estrictamente práctica no ya de hacer méritos ante la horda, sino de evitar que ciertas personas se atrevan a presentar sus candidaturas, o que puedan hacer una campaña electoral libre de amenazas y sabotajes.

Antonio Muñoz Molina, Vísperas municipales

El último marcador que proponemos, al grano, puede enmarcarse entre los reformuladores, que muestran el control de la comunicación por parte del hablante. Estos se comportan como un mecanismo de servocontrol del mensaje con el que el locutor reconduce su discurso hacia el contenido que pretende hacer llegar al oyente después de introducir una serie de digresiones (Fuentes 1996: 59).

Ahora bien, la búsqueda de equivalentes, al igual que en el caso de por así decirlo, no da resultados positivos, dado que, a su valor continuativo, se suma un claro valor focalizador, que difiere sustancialmente de la definición aportada para los operadores de este tipo, según la cual "presentan el miembro del discurso que los incluye como una concreción o ejemplo de una expresión más general" (Martín Zorraquino y Portolés, 1999: 4142). En nuestro texto, sin embargo, el marcador reconduce el discurso centrando la atención del lector en la idea principal aparecida en el pre-texto e indicando que las anteriormente expuestas se apartan del motivo fundamental del discurso. 


\section{CONCLUSIONES}

El análisis de corpora de textos pertenecientes a una determinada tipología pone de manifiesto la conveniencia de que los inventarios de marcadores existentes se amplíen para acoger unidades que nunca han sido incluidas, a pesar de que son efectivamente utilizadas como tales. El tratamiento de textos concretos descubre, por tanto, alternativas capaces también de sacar a la luz relaciones semántico-pragmáticas existentes entre los miembros del discurso.

En nuestro caso, hemos analizado un corpus de textos argumentativos escritos, pertenecientes al estilo periodístico y, en concreto, al género del artículo de opinión, extraídos de tres suplementos dominicales de difusión nacional: Magazine, $A B C$ y El País Semanal. Con este material hemos logrado, en primer lugar, verificar la presencia en los textos de expresiones no catalogadas capaces de funcionar como elementos relacionantes; y, en segundo lugar, detectar funciones textuales aún no reconocidas.

Naturalmente, hemos sustentado nuestro análisis en una serie de parámetros que ha garantizado que las unidades localizadas pertenecen a la categoría de los marcadores en tanto que se adecuan a los principios comúnmente establecidos para esta clase en español: función supraenunciativa, valor deíctico anafórico, significado procedimental, invariabilidad léxica y gramatical, y resistencia a la focalización.

Nuestro estudio ha permitido localizar las siguientes expresiones no catalogadas: se trata de, por así decirlo, hablando de $+S N$, no olvidemos que, de lo que se colige I deduce que y al grano. Confirmada su pertenencia a la clase de los marcadores, hemos especificado el tipo de función textual que introducen.

En el caso de los marcadores se trata de, por así decirlo y al grano, nos hallamos ante marcadores reformulativos. El primero funciona, además, como un reformulador explicativo; el segundo, sin embargo, presenta un matiz diferenciador no considerado en las clasificaciones: define en términos aproximados una idea o concepto presente en el pre-texto. Lo mismo sucede con el marcador al grano, que suma a su valor continuativo un claro valor focalizador que difiere sustancialmente de la definición aportada para los operadores de este tipo.

Por lo que respecta a hablando de $+S N$ y no olvidemos que, actúan como marcadores estructuradores: el primero es de carácter digresor mientras que el segundo se inscribe entre los comentadores.

Por último, de lo que se colige / deduce que es un conector perteneciente al grupo de los consecutivos.

\section{OBRAS CITADAS}

\section{Fuentes primarias}

Antonio Muñoz Molina, "Días de pasión”, El País Semanal. Antonio Muñoz Molina, "Vísperas municipales", El País Semanal. Arturo Pérez-Reverte, "El retablo intermitente de Murcia", $A B C$. Luis Rojas Marcos, "Niños y televisión”, El País Semanal. Manuel Rivas, "El coqueteo con la inmortalidad”, El País Semanal. 
Maruja Torres, "Los bajos fondos", El País Semanal.

Quim Monzó, "El que no fuma”, Magazine.

Quim Monzó, "Lagartos y lechugas”, Magazine.

Quim Monzó, “098”, Magazine.

\section{Fuentes secundarias}

Blecua. 1975. Gramática española. Barcelona: Ariel.

Alonso, P. et al. 2002. Aspects of Discourse Analysis. Salamanca: Ediciones Universidad.

Blakemore, D. 1987. Semantic Constraints on Relevance. Oxford: Blackwell.

Blass, R. 1990. Relevance Relations in Discourse. Cambridge: CUP.

Bosque, I. y V. Demonte, dirs. 1999. Gramática descriptiva de la lengua española. Vol. 3. Madrid: Espasa.

Calsamiglia Blancafort, H. y A. Tusón Valls. 1999. Las cosas del decir. Manual de análisis del discurso. Barcelona: Ariel.

Casado Velarde, M. 1991. "Los operadores discursivos es decir, esto es, o sea y a saber en español actual: valores de lengua y funciones textuales". LEA 13: 87-116.

Casado Velarde, M. 1998. "Lingüística del texto y marcadores del discurso". Eds. A. Martín Zorraquino y E. Montolío. Madrid: Arco/Libros. 55-70.

Díaz Peralta, M. y García Domínguez, M.J. 2004. "El significado pragmático del texto en español. Los signos de puntuación”. Eds. M.J. García Domínguez et al. 83-112.

Domínguez García, N. 2002. La organización del discurso argumentativo: los conectores. (CD). Salamanca: Universidad.

Escandell Vidal, M.V. 1996. Introducción a la pragmática. Barcelona: Ariel.

Fuentes Rodríguez, C. 1987. Enlaces extraoracionales. Sevilla: Alfar.

Fuentes Rodríguez, C. 1996. La sintaxis de los relacionantes supraoracionales. Madrid: Arco/ Libro.

García Domínguez, M.J. y V. Marrero Pulido. "Los marcadores discursivos y su relación con las estrategias de la segmentación del texto en enunciados". Iberoamericana Pragensia. En prensa.

García Domínguez, M.J., G. Piñero Piñero, M. Díaz Peralta y V. Marrero Pulido. Eds. 2004. Lengua Española y Traducción. Las Palmas de Gran Canaria: Servicio de Publicaciones de la Universidad.

Gutiérrez Ordóñez, S. 1997. Temas, remas, focos, tópicos y comentarios. Madrid: Arco/ Libros.

Hyde, J. 2002. "Some Basic Issues in the Study of Language Today: An Introduction to the Analysis of Intersentential Relations in English and Spanish Newspaper Editorials". Eds. P. Alonso et al. 21-44.

Martín Zorraquino, A. y E. Montolío Durán. Eds. 1998. Los marcadores del discurso. Teoría y análisis. Madrid: Arco/Libros.

Martín Zorraquino, A. y J. Portolés Lázaro. 1999. "Los marcadores del discurso". Dirs. I. Bosque y V. Demonte. Vol. 3. 4051-4213.

Marrero Pulido, V. 2004. "La conexión textual implícita: otro procedimiento para la búsqueda del sentido del texto". Eds. M.J. García Domínguez et al. 145-164.

Mederos Martín, H. 1988. Procedimientos de cohesión en el español actual. Santa Cruz de Tenerife: Excmo. Cabildo Insular de Tenerife.

Montolío, E. 2001. Conectores de la lengua escrita. Barcelona: Ariel. 
Piñero Piñero, G. 2001. "El valor de los marcadores del discurso que expresan causalidad en español”. Estudios Filológicos 36: 153-171.

Pons Bordería, S. 1998. Conexión y conectores. Estudio de su relación en el registro informal de la lengua. Valencia: Universidad de Valencia.

Real Academia Española 1999. Ortografía de la lengua española. Madrid: Espasa Calpe.

Sperber, D. y D. Wilson 1986. Relevance. Oxford: Blackwell.

Wilson, D. y D. Sperber. 1993. "Linguistic Form and Relevance”. Lingua 90: 1-25. 